\title{
Australian immunisation registers: established foundations and opportunities for improvement
}

L K Chin (chinlitkim@gmail.com)1, N W Crawford ${ }^{2,3,4}$, G Rowles5 , J P Buttery R,2,3,6 $^{1,2}$

1. Infectious Diseases Unit, Monash Children's Hospital, Melbourne, Australia

2. Surveillance of Adverse Events Following Vaccination In the Community (SAEFVIC), Murdoch Childrens Research Institute, Royal Children's Hospital, Parkville, Australia

3. Department of General Medicine, Royal Children's Hospital, Melbourne

4. Department of Paediatrics, University of Melbourne, Melbourne, Australia

5. Riddell Country Practice, Riddells Creek, Victoria, Australia

6. Department of Paediatrics, Monash University, Clayton, Melbourne, Australia

Citation style for this article:

Chin LK, Crawford NW, Rowles G, Buttery JP. Australian immunisation registers: established foundations and opportunities for improvement . Euro Surveill. 2012;17(16):pii=20148. Available online: http://www.eurosurveillance.org/ViewArticle.aspx?Articleld=20148

The National Immunisation Program Schedule in Australia is formulated and funded nationally under the population-wide Medicare system. The policy is implemented by the eight state and territory jurisdictions. The national immunisation registers consist of the Australian Childhood Immunisation Register (ACIR), and, more recently, the National Human Papillomavirus (HPV) Vaccination Program Register. Moreover, a variety of jurisdiction-based registers and primary care practice software systems exist, which interact with the national registers. General practitioners can obtain reports listing patients under seven years attending their practice and recorded as 'not fully immunised', and immunisation coverage rates for their practice linked to government incentives through Medicare. A 2011 report documents national coverage of $91.8 \%$ fully immunised at 12 months, and $92.6 \%$ at 24 months. The HPV register provides information on vaccination coverage with the potential to link with a register of cervical cancer screening results. Limitations of current national register include inability to easily access immunisation histories beyond seven years of age, and issues of underreporting and timeliness, which impact significantly the immunisation coverage estimates. The linkage of these registers with healthcare outcome data will further enhance public health outcomes by enabling rapid, populationlevel vaccine safety and effectiveness investigations in a nation with a track record as an 'early adopter' of new childhood vaccines.

\section{Introduction}

Defined as population-based, confidential systems containing vaccination histories [1], immunisation registers have been pivotal in ascertaining and improving individual and population-level compliance with vaccination schedules [2]. Used to identify at-risk populations for vaccine-preventable diseases (VPD), registers document and increase vaccination coverage via 'planned' immunisations with recalls and reminders or opportunistic immunisations $[1,3]$. In certain countries, immunisation registers have also been used to assist in the establishment of health policies, as well as to provide a link for parent and provider incentives to improve immunisation rates [4]. More recently, direct linkage of immunisation registers with health outcome data has provided opportunities to examine vaccine safety and effectiveness $[5,6]$.

Currently, the Australian immunisation policy is formulated and funded nationally under the population-wide Medicare system, but implemented by the eight state and territory jurisdictions. The National Immunisation Program (NIP) Schedule covers all Australian population as an approved antigen-based schedule, with potentially multiple manufacturers with nationally approved vaccines purchased centrally. These include diphtheria, tetanus, acellular pertussis, inactivated polio, hepatitis B, Haemophilus influenzae type b (Hib), pneumococcal conjugate (from July 2011, the 13-valent conjugate vaccine replaced the seven-valent conjugate vaccine), rotavirus, measles, mumps, rubella, varicella, group $\mathrm{C}$ meningococcal conjugate and human papillomavirus (HPV) vaccines.

As a result, there is a combination of national- and jurisdiction-based registers, with overlapping and sometimes synergistic functions (Figure 1).

The national immunisation registers consist of the Australian Childhood Immunisation Register (ACIR), and more recently the National Human Papillomavirus 
FIGURE 1

The Australian immunisation registers

\section{Primary care software}

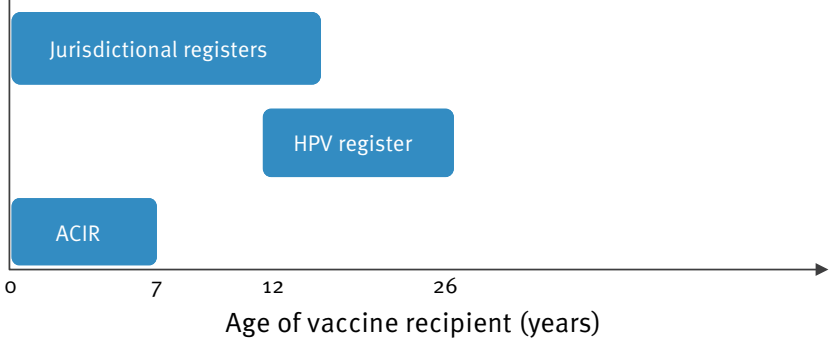

ACIR: Australian Childhood Immunisation Register; HPV: human papillomavirus.

Vaccination Program Register (HPV Register) [7,8]. There are a variety of jurisdiction-based registers, largely aimed at delivering local government-based immunisations, as well as primary care practice software systems that interact with the national registers. As an early adopter of such registries, the experience of this federation of eight states and territories may help illustrate issues facing similar initiatives within Europe. This review will describe the range of immunisation registers in Australia and discuss the benefits, limitations of and challenges for these current systems.

\section{The Australian Childhood Immunisation Register}

The ACIR was introduced in 1996 as part of the Immunise Australia Program, a joint Commonwealth and state/territory government programme, as part of a series of measures to help reduce incidence of VPD in Australia. The ACIR is administered and operated by Medicare Australia, the universal health insurance scheme in Australia [8]. It records details of vaccinations given to children under seven years of age who live in Australia, including vaccine batch details. Since 2001, immunisations administered overseas may be retrospectively recorded if an immunisation provider endorses their validity based on written documentation or confirmation from the previous provider. The ACIR is accessible until a child is 14 years of age and was predominantly established to capture routine NIP vaccines. It is described as the world's first attempt in developing a near-complete population-based immunisation register [1]. It is estimated that $99 \%$ of children in Australia are registered with Medicare (under a unique number for each child) by 12 months of age and those not registered with Medicare by then can be added on via supplementary numbers to the ACIR [1]. Participation of children in the ACIR is opt-out [1]. Based on a survey in 2004 , approximately $3 \%$ of children have incomplete immunisation due to medical contraindications or parents' with conscientious objections to immunisation [9]. These children are still registered with the ACIR after parents have discussed the risks and benefits with a recognised immunisation provider $[1,9,10]$.

\section{Data collection and coverage measurement}

The ACIR receives daily information from direct online notifications, provider software applications (jurisdictional agencies and General Practice management software applications) or paper forms mailed from immunisation providers (Figure 2).

Marked proportional increase of online notifications has been observed, from an initial 6\% in 1998 to $65 \%$ in 2007 [1]. Individuals registered with Medicare Australia will have a unique number that can be used across databases in Australia, although with limitations set by federal privacy legislation. Medicare Australia provides immunisation history statements at milestone ages and for requests at an individual level, information about a child's immunisation status to help determine eligibility for the Australian Government's family assistance payments, and quarterly coverage reports at the immunisation provider, local, national and state level [3]. General practitioners (GPs) are also able to obtain reports listing patients under seven years of age who attend their general practice and who are recorded as 'not fully immunised', and immunisation coverage rates for their practice which is linked to government incentive payments through Medicare.

Immunisation coverage is measured cross-sectionally at the individual or general practice level, and by cohort method at the population level. With the latter, a cohort of children is defined by their date of births in three-month groups. The immunisation status of this cohort is then assessed at the three key milestones of 12 months (for vaccines due at six months), at 24 months of age (for vaccines due at 12 months), and at five years of age (for vaccines due at four years) [8]. Children registered with Medicare who have completed the primary schedule represent the numerator and the total number of children registered in Medicare in the same age cohort represents the denominator $[1,11]$.

To be fully immunised at the milestone ages, the following vaccines need to have been received $[1,12]$ :

- 12 months: three doses of diphtheria (D), tetanus $(\mathrm{T})$, and acellular pertussis $(\mathrm{Pa})$-containing vaccine, three doses of inactivated polio vaccine (IPV), two or three doses of Haemophilus influenzae type b (Hib) vaccine (depending on vaccine type), and two or three doses of hepatitis B vaccine (depending on vaccine type).

- 24 months: three doses of DTPa-containing vaccine, three doses of IPV, three or four doses of Hib vaccine, three or four doses of hepatitis $B$ vaccine (depending on vaccine type) and one dose of measles-mumps-rubella (MMR)- containing vaccine.

- 48 months: four doses of DTPa-containing vaccine, four doses of IPV, and two doses of an MMRcontaining vaccine. 
As per the ACIR overdue rules, an individual is considered overdue one month post the due date for all immunisation time points detailed above [13].

Prior to the introduction of the ACIR, coverage was estimated in 1997 for all age cohorts to be $75 \%$ or less $[1,10]$. The 2011 coverage reports document $91.8 \%$ fully immunised at 12 months, and $92.6 \%$ at 24 months (Figure 3) [14].

For vaccines that require more than one dose, for instance with DTPa vaccine, the child is assumed to have had earlier doses of the vaccine as long as the last dose has been given [3]. This assumption has been validated by a national population-based telephone survey demonstrating this method still underestimates coverage by up to $5 \%$ due to under-reporting [15]. All children should ideally be registered with Medicare by the age of six to eight weeks when the first doses of DTPa, IPV, Hib, rotavirus and PCV7 vaccines are due.
Children not registered with Medicare by this age are provided a supplementary number with ACIR, which may not be linked to their unique Medicare identifier number when finally registered thus reflecting incorrect vaccination histories. The lag time between date of birth and Medicare registration remains significant with lag time beyond two months doubled among those children with missing doses versus those registered promptly after birth $[1,3]$.

The ACIR also plays a role in evaluating immunisation coverage among the indigenous population, representing $2.5 \%$ of the Australian population [16]. The status is recorded as 'indigenous', 'non-indigenous' or 'unknown' as self-reported to Medicare or by the provider to ACIR. Status reporting has improved remarkably with $99 \%$ recorded in 2007 as opposed to $42 \%$ in 2002 for infants aged 12-14 months [17]. Coverage estimates for 12 months and five years are lower for children registered as indigenous by their parent/s and

\section{FIGURE 2}

Flow of information to the Australian Childhood Immunisation Register (ACIR)

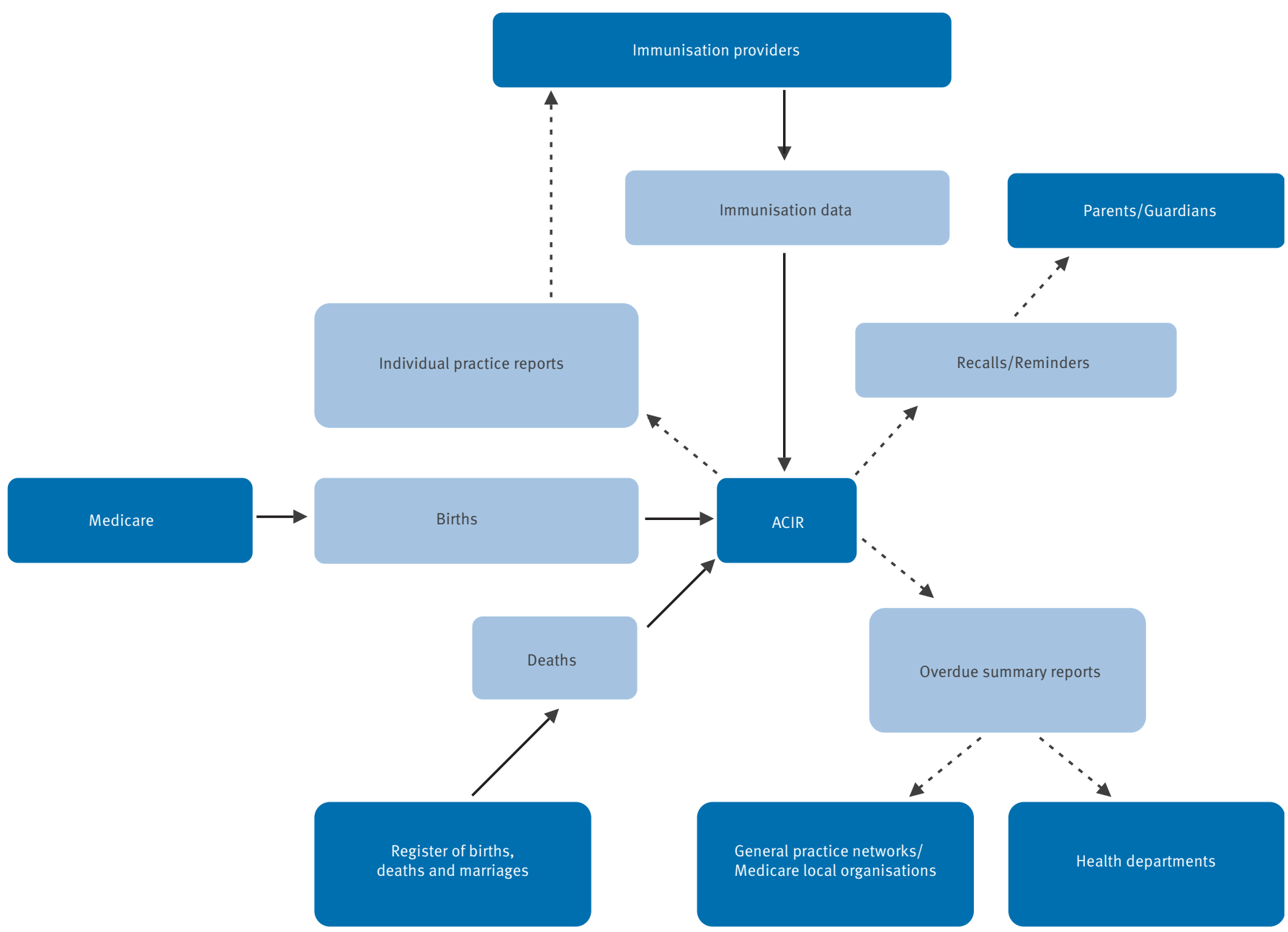

ACIR: Australian Childhood Immunisation Register.

Adapted from: Hull BP, McIntyre PB, Heath TC, Sayer GP. Measuring immunisation coverage in Australia. A review of the Australian Childhood Immunisation Register. Aust Fam Physician. 1999;28(1):55-60 [3].

(c) 2012 Australian Family Physician. Reproduced with permission from The Royal Australian College of General Practitioners. 
have remained stagnant for the last six years, although estimates at 24 months are similar, suggesting timeliness is a major factor [17]. Hepatitis A and 23-valent pneumococcal polysaccharide vaccines recommended and funded only for indigenous children are also documented in ACIR and also show suboptimal coverage estimates $[1,10,18]$.

\section{Factors for improvement in recorded coverage} Immunisation coverage rates have improved with time and better understanding of the function of the ACIR. This could reflect the improvement in provider notification, less delay with increased use of electronic notifications, and the ongoing introduction of combination vaccines contributing to an increase in vaccination coverage [1].

The introduction of immunisation incentives for parents and providers in 1997 and 1998 respectively have also contributed significantly to improved coverage. Parental incentives were introduced to provide a prompt for parents and providers to complete immunisation, or to confirm their conscientious objection or medical contraindication to vaccination. The incomelinked parental incentives include the Maternity Immunisation Allowance (MIA) and Child Care Benefit (CCB) [1]. Paid at two separate time points, the MIA, a non-taxable amount of AUD 258 (approximately EUR 203) can be claimed on or before the child's fifth birthday if the child is shown to have completed immunisation (or has a registered conscientious objection or medical contraindication to vaccination) [19]. However, from July 2012, MIA will be replaced by the existing Family Tax Benefit Part A supplement where children must be fully immunised for parents to receive AUD 726 (approximately EUR 571) for each child at each immunisation checkpoint at ages one, two and five years [20]. The CCB incentive partially reimburses parents who use approved or registered childcare and the amount depends on the family's yearly income, but can potentially be a much larger financial benefit than the MIA [21]. It was suggested parental incentives played an independent role in the increase of completed immunisation coverage at 24 months [1].

For the immunisation providers in primary healthcare settings, the General Practice Immunisation Incentive (GPII) Scheme was introduced in 1998 to encourage immunisation notifications and to achieve at least $90 \%$ of practices to fully immunise $90 \%$ of children aged below seven years attending their practices [22]. In 2008, the federal budget ceased the GPII Service Incentive Payment (SIP). The SIP was a payment (AUD 18.50) made for notification by the provider of completion of vaccination at a certain milestone age. To date, discontinuation of SIP has not affected immunisation coverage, however longer term analysis may be warranted [23]. The other two components of the GPII scheme remain, namely the Information Payments (up

\section{FIGURE 3}

Australian Childhood Immunisation Register (ACIR) standard coverage by age cohort, December 1998-May 2011

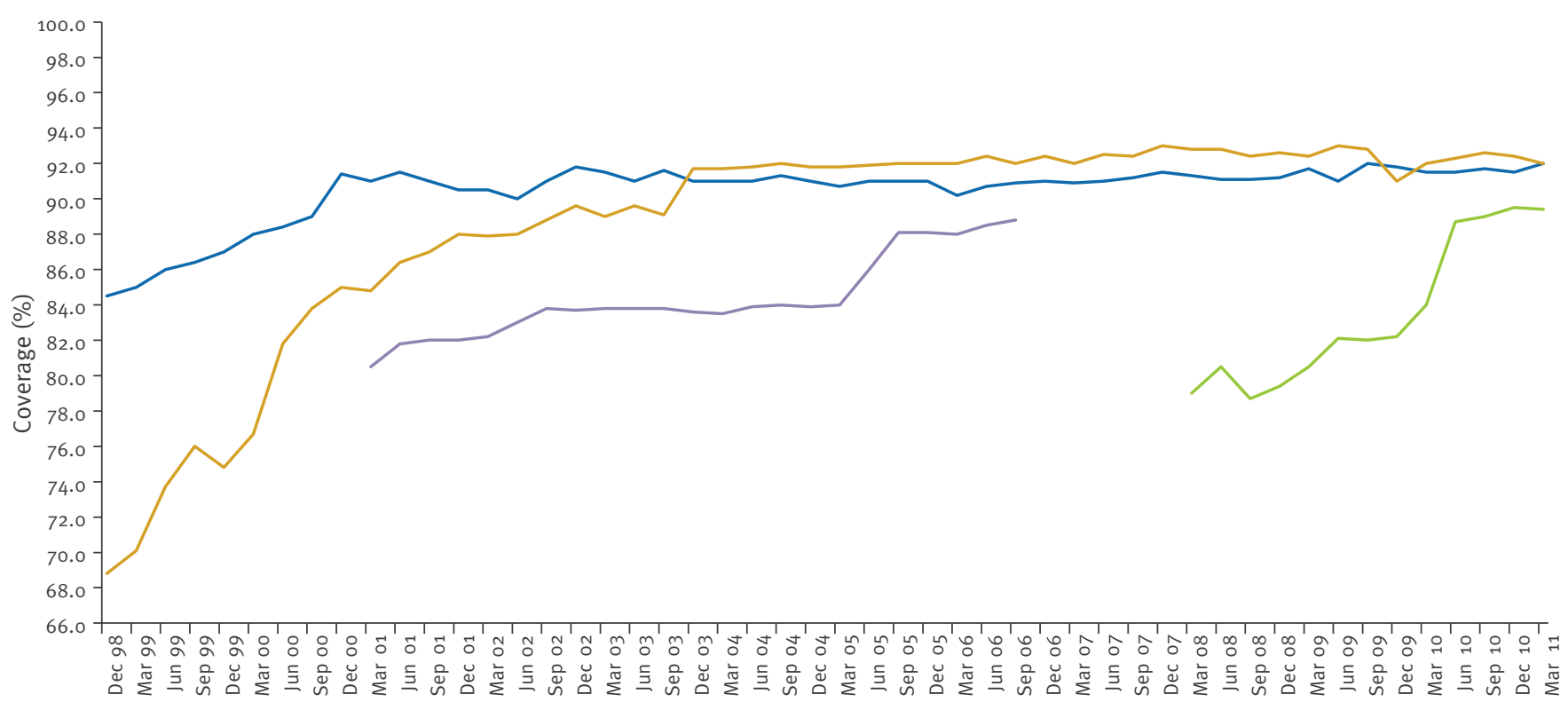

Quarter of processing

$$
\text { - 12-<15 months - 24-<27 months - 60-<63 months - 72-<75 months }
$$

The coverage at five years of age is for vaccines due at the age of four-five years; this was changed in December 2007 from the age of six years. Source: Australian Childhood Immunisation Register (ACIR). Standard Coverage for Australia [14]. 
to AUD 6 (approximately EUR 5), paid to all immunisation providers after notification of administration of all the milestone age NIP vaccines) and the GPII outcome payments (for practices with $\geq 90 \%$ of fully immunised children) $[10,22]$.

\section{The National Human Papillomavirus Vaccination Register}

The HPV register was legislatively enabled in 2007 and became operational in $2008[24,25]$. The Australian Government funded the quadrivalent vaccine $4 \mathrm{vHPV}$, (Gardasil, Merck, New Jersey, USA) as part of the programme in 2007. The bivalent 2VHPV vaccine (Cervarix, GSK, Uxbridge, UK) was licensed in late 2008, but the national programme in Australia is using the $4 \mathrm{VHPV}$ vaccine. This programme is targeted at pre-adolescent and adolescent females, with a funded ongoing schoolbased vaccination for 12- and 13-year-old girls. A twoyear catch-up programme was also initially funded by the Australian Government for 13-18-year-old girls in schools and 18-26-year-old women through general practice and community-based programmes [25].

The Victorian Cytology Service currently operates the HPV register, which is also responsible for the Victorian
Cervical Cytology Register [26]. Prior to the establishment of the register in 2008, data from schools were held at local or State Health Department levels while GP-held data were recorded and held as instructed by the Australian General Practice Network [25]. HPV vaccine data can be submitted via different jurisdictional electronic immunisation databases (mostly via school immunisation programme), direct data entry to the HPV register web portal and GP notification via mail or fax from practice management software (Figure 4) [25]. To encourage registration, GPs were invited to register with the HPV register and on notification of a valid HPV vaccine dose, GPs were remunerated AUD 6 (approximately EUR 5) per vaccination encounter. This incentive attracted over $96 \%$ of GPs invited to register by March 2010, and was discontinued in June 2010, following the completion of the HPV vaccination catch-up programme [25].

The register provides information on vaccination coverage with the potential to link with a disease register of cervical cancer screening results. Coverage in Australia is currently calculated by age of all eligible females in the programme i.e. 12-26-year-olds in 2007 and 12-13-year-olds each year [25]. The numerator for

\section{FIGURE 4}

National Human Papillomavirus Vaccination Program Register (NHVPR) operations: data inputs and outputs, Australia

INPUTS

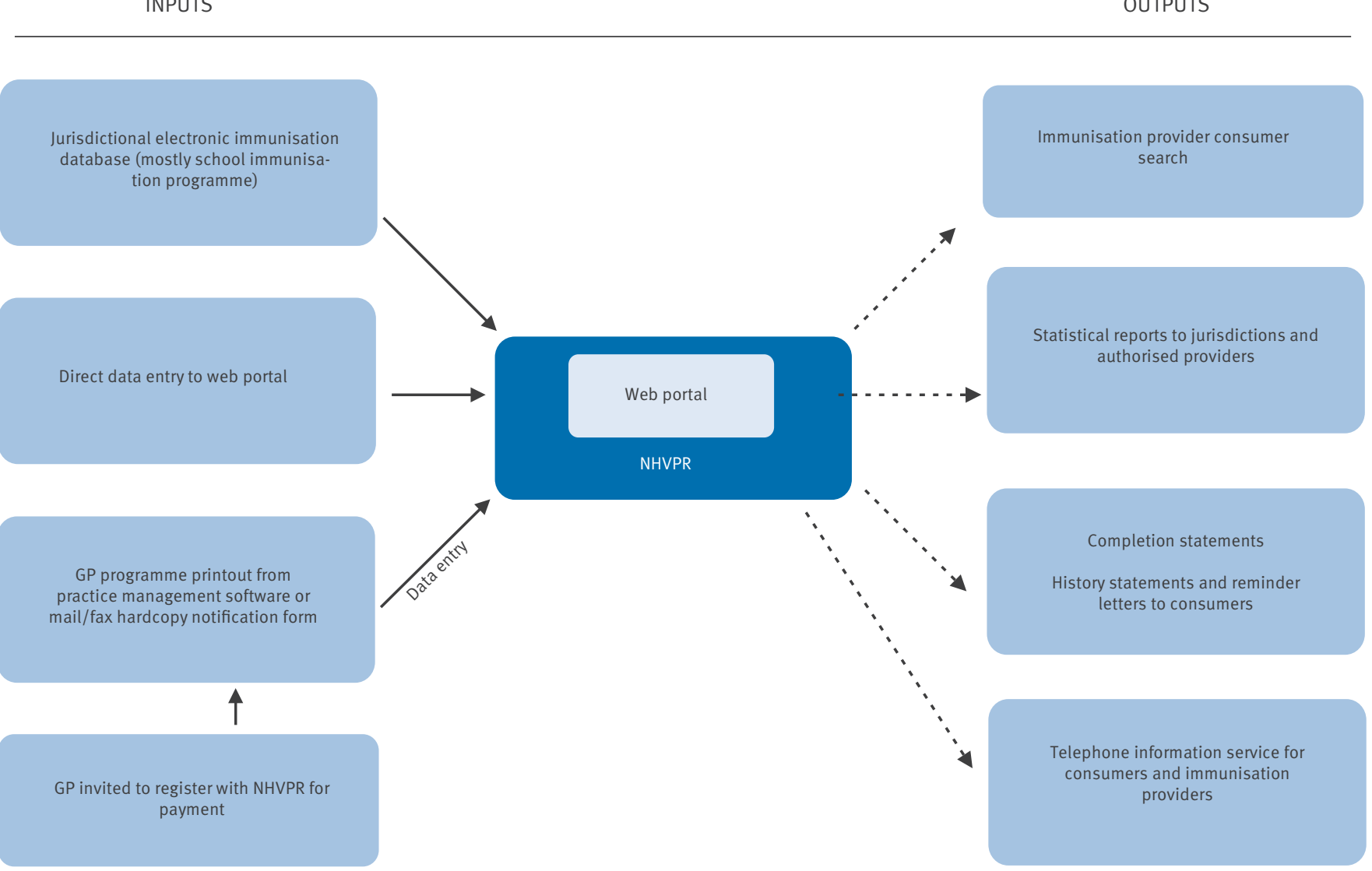

GP: General practitioner; NHVPR: National Human Papillomavirus Vaccination Program Register.

Source: Gertig DM, Brotherton JM, Saville M. Measuring human papillomavirus (HPV) vaccination coverage and the role of the National HPV Vaccination Program Register, Australia. CSIRO PUBLISHING. Sexual Health. 2011;8(2):171-8.

Available from: http://www.publish.csiro.au/paper/SH10001.htm [25]. 
coverage is the number of females in the target population who have received three $4 \mathrm{VHPV}$ doses. Coverage with one or two doses of the vaccine has also been calculated [25]. Recent data from the HPV register indicate promising 4VHPV coverage of the target group of 12-15-year-olds with $72-73 \%$ having completed three doses. International standardised coverage methods have yet to be agreed for $4 \mathrm{VHPV}$, limiting comparisons of the effectiveness of HPV vaccines $[24,25]$.

The HPV register also plays an important role in providing consolidated information on school and primary care vaccine doses, which would be useful to follow up on overdue vaccinations. In the future, this information will also provide the opportunity to notify young women if a booster dose is required [25]. A limitation of this HPV register was that it was not established before the National HPV immunisation programme commenced in 2007 and does not capture co-administered vaccines. It has also been proposed that Australia will soon begin immunising 12-13-year old boys under the NIP [27].

There have been calls internationally for HPV vaccination registers to be combined with a cervical cancer screening register, to incorporate vaccination status, cytology, histology and HPV DNA test results [25, 26]. $A$ recent ecological study analysing the early effects of the HPV vaccination programme on cervical abnormalities in Victoria showed a decrease of $0.38 \%(95 \%$ confidence interval: $0.61-0.16 ; p=0.003$ ) in high-grade cervical abnormalities in the three years after vaccine introduction, compared with four years before [26]. Linking of cervical cytology to vaccination status would allow testing of a causal link between HPV vaccines reducing cervical abnormality rates [26].

\section{Jurisdictional vaccination registers}

All jurisdictions with the exception of Tasmania and the Australian Capital Territory have separate registers: to record adolescent vaccines administered in the school-based programmes (New South Wales, Western Australia); school and local government- administered child and adolescent vaccines (South Australia, Victoria); or all childhood and NIP vaccinations administered (Queensland, Northern Territory). All are managed at the jurisdictional level, with the exception of the Immunisation Provider System (ImPS) in Victoria and South Australia, where electronic records are held at local government level, and all upload directly to ACIR or the HPV Register. Local reports of vaccine coverage are generated from ImPS and forwarded to the state Departments of Health for completion of vaccination records [28].

\section{Primary care software}

In 2007, it was estimated that Australian GPs were providing $71 \%$ of recorded vaccinations on the ACIR, with substantial jurisdictional variation [3]. Prior to the introduction of ACIR, many GPs had implemented various non-compatible decentralised immunisation record systems [29]. The introduction of the ACIR was seen as addressing this issue and to improve population vaccination recording.

There are a number of commercial providers of GP practice software systems, with the ability to interact directly with ACIR and indirectly with the HPV Register. Varying in their immunisation recording capabilities, they represent the major data records for NIP vaccines for adults (e.g. pneumococcal and influenza vaccinations for the indigenous, elderly and 'medical at risk') and non-NIP vaccines (e.g. travel vaccinations), jurisdiction-funded vaccines e.g. adult pertussis (dTpa) and adult MMR vaccines, funded non-NIP vaccines requiring co-payments e.g. 'medical at risk' adult pneumococcal and privately prescribed vaccines). Records are held at practice level, but it is possible for anonymised data directly linking immunisations with subsequent attendances for healthcare at the practice to be extracted across multiple practices. The recently announced National Prescribing Service 'MedicineWatch' programme linking medicine use with potential adverse outcomes in primary care is a potential example of these systems. A limitation is that the GP software is provided by commercial companies, not the Australian Government, hence changes in the NIP are often not reflected in the software until the company decides to run an upgrade.

Other registers: $Q$ fever vaccination register The $Q$ fever vaccination register is an industry-based register run by the Meat and Livestock Australia (MLA) corporation for recording vaccination and immunity status for the federally-funded $Q$ fever vaccine in humans. It is accessible via the internet to medical practitioners and meat processors [30].

\section{Limitations of the current immunisation registers}

The absence of immunisation histories beyond seven years of age is a critical limitation of the ACIR. Whilst records are now available up to 14 years of age, late childhood and adolescent vaccines are not captured in ACIR. There has been a call for a 'whole-of-life' immunisation register that will record child, adolescent and adult immunisations including tetanus, influenza and pneumococcal immunisations [31,32]. Currently selfreporting of these vaccinations have been described as problematic with limited validity and poor coverage estimates of $71-79 \%$ of influenza vaccine and $51-53 \%$ of PPV23 [31]. It is anticipated that with a 'whole-oflife' immunisation register, health outcomes can be improved further by identifying missed vaccinations and prevent over-vaccination [32]. The HPV register for instance would seem an appropriate extension of the ACIR. Other registers such as the Australian Donor Organ register and the bowel cancer screening register have been suggested to be included in this 'whole-oflife' register [32]. In 2006, the Australian Government Department of Health and Ageing funded a scoping study for the redevelopment of ACIR, the results of which are still pending [32]. A National Immunisation 
Strategy commissioned in 2010 and yet to be released, is anticipated to consider this issue and will hopefully provide stimulus for action on a 'whole of life' register.

A well-documented cause of lower immunisation coverage particularly with $A C I R$ is inadequate reporting of immunisation encounters by immunisation providers $[1,33]$. ACIR has been reported to underestimate immunisation coverage by up to $5 \%$ in most states [15]. Moreover, electronic exchange of information is unilateral between primary care software systems and ACIR resulting in the tedious task of manually updating vaccines already on ACIR through individual requests or manual practice reports. A study evaluating home immunisation in a socially disadvantaged area also highlighted under-reporting with discrepancies of $11-14 \%$ between ACIR vaccination status versus actual vaccination status when checked prior to the commencement of the study [34].

Other limitations in Australia include the unreliable reporting of 'additional' NIP vaccines recommended for special at-risk patient groups in ACIR and the potential impact upon GP reporting to the HPV Register after the removal of the financial incentive for notification of vaccination. In addition, ACIR coverage calculations and GPII outcome exclude established vaccines introduced after 1996 (thus excluding rotavirus, pneumococcal conjugate, group $C$ meningococcal, and varicella vaccines). However, this issue will be addressed with the latter three vaccines being included in the list of immunisations to be assessed as fully immunised from July 2013 [20]. There is also the possibility of linking ACIR to electronic health records as a way to progress vaccine effectiveness evaluations as well as rapidly investigate vaccine safety signals at jurisdiction, national or international level [35]. However, federal and jurisdictional privacy regulations and the extreme difficulty of linking immunisation databases with healthcare outcomes for those patients, limits the Australian ability to investigate potential vaccine safety signals [36]. ACIR data have been used to determine the expected number of intussusceptions following rotavirus vaccination in a post-marketing safety study identifying a potential association of new rotavirus vaccines with intussusceptions in Australia [5]. It has also been linked with hospital data to illustrate a link between MMR vaccine and idiopathic thrombocytopenic purpura [6].

\section{Conclusion}

Currently, Australia boasts a near-complete population-based childhood immunisation register with the ACIR. However, the obvious void of immunisation histories beyond seven years of age means that calls for a 'whole-of-life' register are ongoing. In addition, it only covers NIP routine vaccines introduced before 1996, and the HPV register sits separate to ACIR. These registers could provide a framework to expand immunisation registers linked to electronic health records. Limitations of current registers are still widespread, particularly with issues of under-reporting and timeliness, which impact significantly to immunisation coverage estimates. Nevertheless, these available immunisation registers form a fundamental platform for further improvement in immunisation coverage. The linkage of these registers with healthcare outcome data will further enhance public health outcomes by enabling rapid, population-level vaccine safety and effectiveness investigations in a nation with a track record as an 'early adopter' of new childhood vaccines.

\section{Conflicts of interest}

NWC and JPB have acted as chief investigators for epidemiological studies sponsored by vaccine manufacturers (CSL) and serological testing (Merck). All payments, including for sitting on advisory boards (NWC), data safety monitoring boards (JPB), lecturing (NWC) and travel expenses for attendance at scientific meetings, are paid directly to an administrative fund held by Murdoch Childrens Research Institute.

GR has accepted funding from vaccine manufacturers (GSK) to attend two scientific meetings and to sit on an advisory board, and has lectured at GP education events that have been sponsored by vaccine manufacturers (CSL, GSK, Wyeth, Sanofi). 


\section{References}

1. Hull BP, Deeks SL, McIntyre PB. The Australian Childhood Immunisation Register-A model for universal immunisation registers? Vaccine. 2009;27(37):5054-60.

2. Australian Bureau of Statistics (ABS). 4813.0.55.001 Occasional Paper: Vaccination Coverage in Australian Children - ABS Statistics and the Australian Childhood Immunisation Register (ACIR), 2001. Australia: ABS; 2001. Available from: http://www.abs.gov.au/ausstats/abs@.nsf/ Latestproducts/4813.0.55.001Main\%20Features12001?opendo cument $\&$ tabname $=$ Summary $\&$ prodno $=4813.0 .55 \cdot 001 \&$ issue $=2$ $001 \&$ num $=\&$ view $=$

3. Hull BP, McIntyre PB, Heath TC, Sayer GP. Measuring immunisation coverage in Australia. A review of the Australian Childhood Immunisation Register. Aust Fam Physician. 1999;28(1):55-60.

4. Morrato EH, Elias M, Gericke CA. Using population-based routine data for evidence-based health policy decisions: lessons from three examples of setting and evaluating national health policy in Australia, the UK and the USA. J Public Health (Oxf). 2007;29(4):463-71.

5. Buttery JP, Danchin MH, Lee KJ, Carlin JB, McIntyre PB, Elliott Ej, et al. Intussusception following rotavirus vaccine administration: post-marketing surveillance in the National Immunization Program in Australia. Vaccine. 2011;29(16):3061-6.

6. Gold M, Dugdale S, Woodman RJ, McCaul KA. Use of the Australian Childhood Immunisation Register for vaccine safety data linkage. Vaccine. 2010;28(26):4308-11.

7. The National Human Papillomavirus (HPV) Vaccination Program Register (NHVPR) [Internet]. East Melbourne Victoria: NHVPR. [Accessed 30 Jul 2011]; Available from: http://www.hpvregister. org.au/Default.aspx

8. Australian Government. Department of Human Services. Medicare. About the Immunisation Register. Australian Government; 18 Mar 2010. Available from: http://www. medicareaustralia.gov.au/public/services/acir/about.jsp

9. Lawrence GL, Hull BP, MacIntyre CR, McIntyre PB. Reasons for incomplete immunisation among Australian children. A national survey of parents. Aust Fam Physician. 2004;33(7):568-71.

10. Hull BP, Mahajan D, Dey A, Menzies RI, McIntyre PB. Immunisation coverage annual report, 2008. Commun Dis Intel. 2010;34(3):241-58.

11. Lister S, McIntyre PB, Burgess MA, O’Brien ED. Immunisation coverage in Australian children: a systematic review 19901998. Commun Dis Intel. 1999;23(6):145-70.

12. National Centre for Immunisation Research and Surveillance (NCIRS). Coverage Information. NSW: NCIRS; [Accessed 5 Sep 2011]. Available from: http://www.ncirs.edu.au/immunisation/ coverage/index.php

13. Australian Government. Medicare Australia. Australian Childhood Immunisation Register. National Due and Overdue Rules for Childhood Immunisation. Australian Government. Jan 2009. Available from: http://www.medicareaustralia.gov.au/ provider/patients/acir/files/national-due-and-overdue-rulesfor-childhood-immunisation.pdf

14. Australian Government. Department of Human Services. Medicare. Australian Childhood Immunisation Register (ACIR) statistics. Australian Government. 10 Feb 2012. Available from: http://www.medicareaustralia.gov.au/provider/patients/acir/ statistics.jsp

15. Hull BP, Lawrence GL, MacIntyre CR, McIntyre PB. Immunisation coverage in Australia corrected for underreporting to the Australian Childhood Immunisation Register. Aust N Z J Public Health. 2003;27(5):533-8.

16. Australian Bureau of Statistics (ABS). 1370.0 - Measures of Australia's Progress, 2010. Australia: ABS. [Accessed $18 \mathrm{Apr}$ 2012]. Available from: http://www.abs.gov.au/ausstats/abs@. nsf/Lookup/by\%20Subject/1370.0 2010 Chapter Aborigin al\%20and $\% 20$ Torres $\% 20$ Strait $\% 2$ olslander $\% 2$ opeoples $\% 20$ (3.5)

17. Hull BP, Deeks S, Menzies R, Mclntyre PB. What do we know about 7VPCV coverage in Aboriginal and Torres Strait Islander children? A 2007 update. Commun Dis Intel. 2008;32(2):257-60.

18. Hull BP, McIntyre PB, Couzos S. Evaluation of immunisation coverage for aboriginal and Torres Strait Islander children using the Australian Childhood Immunisation Register. Aus N Z J Public Health. 2004;28(1):47-52.

19. Australian Government. Department of Human Services. Centrelink. Maternity Immunisation Allowance. Australian Government. [Accessed 31 Jul 2011]. Available from: http:// www.centrelink.gov.au/internet/internet.nsf/payments maternity_allow.htm

20. Australian Government. Department of Health and Ageing. Immunise Australia Program. Frequently Asked Questions:
Changes to National Immunisation Schedule and Related Payments. Australian Government. [Accessed 28 Mar 2012). Available from: http://immunise.health.gov.au/internet/ immunise/publishing.nsf/Content/faq-related-payments

21. Australian Government. Department of Human Services. Centrelink. Child Care Benefit. Australian Government. [Accessed 31 Jul 2011]. Available from: http://www.centrelink. gov.au/internet/internet.nsf/payments/childcare_benefit.htm

22. Australian Government. Department of Human Services. Medicare Australia. General Practice Immunisation Incentive (GPII). Australian Government. [Accessed 1 Aug 2011]. Available from: http://www.medicareaustralia.gov.au/provider/ incentives/gpii/index.jsp

23. Hull B, Dey A, Mahajan D, Menzies R, McIntyre PB. Immunisation coverage annual report, 2009. Commun Dis Intel. 2011;35(2):132-48.

24. Australian Government. Department of Health and Ageing. Immunise Australia Program. Human papillomavirus (HPV). Australian Government. [Accessed 31 Jul 2011]. Available from: http://www.immunise.health.gov.au/internet/immunise/ publishing.nsf/Content/immunise-hpv

25. Gertig DM, Brotherton JM, Saville M. Measuring human papillomavirus (HPV) vaccination coverage and the role of the National HPV Vaccination Program Register, Australia. Sex Health. 2011;8(2):171-8.

26. Brotherton JM, Fridman M, May CL, Chappell G, Saville AM, Gertig DM. Early effect of the HPV vaccination programme on cervical abnormalities in Victoria, Australia: an ecological study. Lancet. 2011;377(9783):2085-92.

27. Australian Government. Department of Health and Ageing. PBAC Outcomes Information for Pharmaceutical Companies. Australian Government. [Accessed 16 Apr 2012]. Available from: http://www.health.gov.au/internet/main/publishing.nsf/ Content/pbac-outcomes-info

28. Victoria Government. Department of Health. Immunisation Program. Guidelines for immunisation practice in local governments. Victoria Government. [Accessed 1 Aug 2011]. Available from: http://docs.health.vic.gov.au/docs/doc/7 92CED34C9A708BACA2579110002788C/\$FILE/guidelines_ immunisation_practice_local_governments.pdf

29. Crampton RM. The Australian Childhood Immunisation Register (ACIR). Aust Fam Physician. 1995;24(8):1392-3.

30. Australian Q Fever Register [Internet]. [Accessed 5 Sep 2011]. Available from: http://www.qfever.org/index.html

31. Skull SA, Nolan TM. Australia needs an expanded immunisation register for further improvements in vaccine delivery and program evaluation. Med J Aust. 2007;187(9):504-5.

32. Australian Government. Department of Health and Ageing. Australian Childhood Immunisation Register - Redevelopment scoping study. Australian Government. [Accessed 31 Jul 2011]. Available from: http://www.health.gov.au/internet/budget/ publishing.nsf/content/budget2006-hfact62.htm

33. Haynes K, Stone C. Predictors of incomplete immunisation in Victorian children. Aust N Z J Public Health. 2004;28(1):72-9.

34. Bond LM, Nolan TM, Lester RA. Home vaccination for children behind in their immunisation schedule: a randomised controlled trial. Med J Aust. 1998;168(10):487-90.

35. Coiera E. Do we need a national electronic summary care record? Med J Aust. 2011;194(2):90-2.

36. Gold MS, Effler P, Kelly H, Richmond PC, Buttery JP. Febrile convulsions after 2010 seasonal trivalent influenza vaccine: implications for vaccine safety surveillance in Australia. Med Aust. 2010;193(9):492-3. 